\title{
External Quality Cues' Impact on Developing Cigarette Brand Image
}

\author{
Tahmoures Hasangholipour \\ Faculty of Management, University of Tehran, 14155-6311, Tehran, Iran \\ E-mail: thyasori@ut.ac.ir \\ Mohsen Nazari \\ Faculty of Management, University of Tehran, 14155-6311, Tehran, Iran \\ E-mail: mohsen.nazari@ut.ac.ir \\ Mehdi Ghafoury (Corresponding author) \\ Faculty of Management, University of Tehran, 14155-6311, Tehran, Iran \\ E-mail: m.ghafoury@ut.ac.ir
}

Received: May 11, 2013 Accepted: July 4, $2013 \quad$ Published: December 5, 2013

doi:10.5296/bms.v4i2.4673 URL: http://dx.doi.org/10.5296/bms.v4i2.4673

\begin{abstract}
We examined the causal effect of external quality cues on brand image of cigarettes, in the absence of any internal cue, among Iranian adults. The experimental research employed a $3 * 2 * 2$ factorial design with three levels of graphic quality, two levels of price and two levels of product variety signs. Results suggested that all three factors had an impact on brand image, though the effects varied noticeably among smokers and non-smokers. The effect of moderating variables was also studied and results indicated that a respondent's profile and status, particularly his age, education, marital status and number of cigarette-consuming companions could influence the way he interprets the quality cues. Moderating factors were formulated as a new variable we called it permeability.
\end{abstract}

Keywords: Brand image, Quality cues, Permeability, Graphic quality, Price, Variety signs 


\section{Introduction}

Quality cues have long been studied as customers' tools to objectify the intangible idea of quality; hence reduce uncertainty and make better purchase decisions possible. (Olson, 1977; Cooper, 1969)

While literature suggests that internal quality cues have greater effect on perceived quality than external cues do (Olson, 1974), there are contexts in which internal quality cues are weak or hard to distinguish, and external quality cues play the main role in customer judgment (Langhe,2011). Furthermore, there are intense competitive situations in which no guidance for customers neither a conventional advertising vehicle for marketers is available; except of package appearance, price and some other outward features.

Iranian cigarette market is a good example of the aforementioned situation. Strict laws against cigarette advertisement are enforced in the country, with the main pressure on the local tobacco manufacturer. While Iranian Tobacco Company (ITC) is the sole manufacturer of cigarettes in Iran, its share of 60 billion cigarettes market is one third of volume and only one tenth of value. ITC has struggled to compete with global tobacco companies and lack of branding opportunity has deterred its attempts, whereas the foreign competitor, even newcomers, are able to gain remarkable market shares with high brand equity (Qomlaqi \& Ghafoury, 2011).

Central to brand equity calculations, is the concept of brand image. Brand image has been defined as customer's general impression of a brand (Dobni \& Zinkhan, 1990; Aaker \& Joachimsthaler2000). In spite of the fact that brand image is an accumulation of experiences over time and gained from different sources (Keller, 2003), we can think of an early phase of developing brand image that happens in customer's first encounters with brand. This transient phase can be or be not reinforced with congruent long term messages from brand source, but the first impression is likely to linger on (Muthukrishnan \& Chattopadhyay, 2007).

The first encounter to brand is quite likely to be in a shelf, where physical characteristics, price and signs indicating product diversity can affect customer judgment. In fact, literature supports the idea that above mentioned indicators, known as external quality cues, can shape brand image. Zeithaml (1990) has developed a model to demonstrate the relationship between quality cues and brand image, mediated by perceived quality construct.

In present research we aimed to try how effective external quality cues are in developing a perception of brand image. We selected three external quality cues of "price", "product variety signs" and "quality of graphic design" and examined their causal effect on customer perception of brand image. In this study, based on Biel's work (1993), we considered the brand image as a composition of two components; product image and user image.

H1: Higher quality of package graphic will result in more favorable brand image.

H2: Adding signs of product diversity will result in more favorable brand image. 
H3: Higher price will result in more favorable brand image.

Of course, there are oppositions against every branding attempt in tobacco industry, and social responsibility of marketing should be carefully taken into account. Inevitably, we are concerned about the way non-smokers conceive brand image aroused by enhanced quality cues.

H4: The impact of package graphic on cigarette brand image is alike among smokers and non-smokers.

H5: The impact of variety signs on cigarette brand image is alike among smokers and non-smokers.

H6: The impact of price on cigarette brand image is alike among smokers and non-smokers.

Finally, from the marketing communication point of view, it's essential to realize the factors influencing the relationship between a brand message and customer perception of a brand. These moderating variables have been studied in several researches. Zinkhan and Hong (1991) tried to explain the relationship between self concept and advertising effectiveness. Fry (1971) studied the role of personality traits in choosing cigarette brands, moderated by gender and socioeconomic situation. Batra and Sinha (2000) examined moderating effect of customer's perceived risk on brand preference. Gwinner (1997) studied the relationship between event image and brand image of the event sponsor and evaluated the moderating effect of internal and external factors like degree of similarity, product involvement, event frequency and level of sponsorship. We specified "smoking profile" and "socioeconomic situation" as possible moderators, that influence the way a customer perceives brand messages and develops a brand image. We tried to integrate the moderating variables and called the resulted construct "permeability", to pinpoint internal nature of moderating factors.

H7: An individual's smoking profile and socioeconomic situation affect his interpretation of quality cues.

\section{Method}

We conducted an experimental research, adopting 3x2x2 factorial design (with 3 levels of graphic quality, 2 levels of price and 2 levels of variety signs). Data were collected using self-administered questionnaire. Respondents answered the questions while looking at a randomly selected picture out of 12 possible combinations of 3 independent variables. Research population consisted of all above 16 yrs old male citizens of Tehran (more than 3 000 000), and sample size was calculated, using Cohen table (1988), desiring the effect size of 0.35 , power of 0.8 and significance level of 0.95 . We assigned 20 subjects to each of 12 group, numbering 240, where exactly half of each group were smokers.

\subsection{Treatment}

We presented 3 factors of "graphic quality", "price" and "variety signs" via 12 pictures of a hypothetical Iranian cigarette pack named "Arian" (appendix 1). To achieve test validity, we 
took below mentioned points into consideration: a) three levels of graphic design quality were comparable to the best, worst and intermediate cigarette packs of established brands in Iranian market. b) The level of graphic quality was specified and confirmed by a panel of graphic/packaging experts. Respondents were requested at the beginning to categorize the packs' graphic design as good, average or bad; and only those who had the same perception of graphic level as the experts had specified, were asked to complete the questionnaire. This way, we eliminated the distortion created by aesthetic differences. c) We controlled the unwanted effect of various elements of a package such as color, shape, name, texts, material and etc. by unifying them across all 3 graphic levels, and only those elements related to the graphic designing quality differed. d) Two levels of price were selected to be comparable to the most expensive (Marlboro=55 000 Rls.) and cheapest (Zica=15 000Rls.) cigarettes common in local market. Illustrating a single pack represented the low level of variety, while multi packs with different colors showed the higher level of variety in product.

\subsection{Questionnaire}

Questionnaire included two sections: first, questions measuring individuals' perceptions of displayed cigarette brand (consisted of product image and user image), and second, information of respondents' smoking profile, demographic data and socioeconomic status. After conducting pre-test, we amended ambiguous questions and then after re-test with 30 individuals, shortened the first section of questionnaire to 17 and second section to 16 questions. Questions related to product image measured respondent attitude toward expected quality of illustrated cigarette, by attributing a set of typical descriptions to it in a Likert scale. These descriptions were: "to have a bad smell", "being harsh on throat", tasting good", "being original", "been processed under hygienic condition", "being genuine" and "being of a good quality". Questions related to brand user image asked respondent's guess about the likely attributes of a typical smoker of the illustrated cigarette. These attributes were: "good dresser", "educated", "fashionable", "successful", "sociable", "high class", "attractive", "special" and "having an important job".

"Smoking profile" of respondent consisted of a set of data like number of cigarette-consuming relatives in childhood, number of cigarette-consuming acquaintance at present, number of cigarettes smoked in the past 10 days, the age he smoked the first cigarette, brand and price of current cigarette, being a quitter and probability of smoking in next 30 days. Socioeconomic status questions were about age, marital status, education, having a full time or part time job and monthly income.

\subsection{Data Collection Process}

Data were collected using paper and pencil method during December and January of 2012. Sampling was not totally randomized, yet we endeavored to have a fairly representative sample. Therefore, we used a technique in which convenience sampling was conducted in 120 locations randomly assigned on a digital map (two respondents in each location, one of them was smoker and one non-smoker). 


\subsection{Statistical Analysis}

We analyzed data using SPSS software version 19. Full factorial ANOVA investigated the impact of each factor by comparing mean value of dependent variable (brand image) across 12 groups. Besides the main effects, ANOVA exhibited the interaction of factors. For above said analysis, homogeneity of variances was examined through Levene's test. To study the effect of moderating variables, we performed a linear regression analysis. The moderating effect of "permeability" variables was calculated by entering the product of standardized values of moderating variable and each independent variable in a regression equation.

\section{Results}

We achieved a normal distribution of respondents' ages. Among 240 individuals, $47(19.6 \%)$ were 16 to 25 years, $74(30.8 \%)$ were 26 to 35 years, 60 (25\%) were 36-45, 36 (15\%) were 46-55 and 23 individual (9.6\%) were older than 55 years. The dependent variable, brand image, also had a normal distribution.

ANOVA through the whole sample (smoker/non-smokers) showed significant causal relationships between each factor and dependent variable with following effect sizes $\left(\boldsymbol{\eta}^{2}\right)$ : "graphic" 0.421 (sig.=0.000), "price" $0.203 \quad$ (sig.=0.000) and "variety signs" 0.019 (sig.=0.037). No mutual effects were observed between factors. Adjusted $\mathrm{R}^{2}$ was no more than 0.484 . However, these results were not totally trustable because of a significant levene's test.

To get more clear results we split the sample to two equal subgroups of smokers and non-smokers, using split file command in SPSS. The ANOVA result can be seen in table 1. The difference between smoker and non-smoker subgroups can be clearly observed. The factor "variety signs" proved to be not effective on brand image development for non-smokers where it was a meaningful cue for smokers. The interactions between factors were also significant. All in all, comparing $\mathrm{R}^{2}$ coefficients between two subgroup ANOVAs was telling.

Based on above mentioned results, with $95 \%$ confidence, $\mathrm{H} 1$ and $\mathrm{H} 3$ were accepted while $\mathrm{H} 2$ was rejected for a significant null hypothesis. Hypothesis 4,5 and 6 were also accepted. 


\section{Macrothink}

Business Management and Strategy

ISSN 2157-6068

2013, Vol. 4, No. 2

Table 1. ANOVA results after splitting the sample to two subgroups (research findings)

\begin{tabular}{|c|c|c|c|c|c|c|c|}
\hline smoker-nonsmoker & Source & $\begin{array}{l}\text { Type III Sum } \\
\text { of Squares }\end{array}$ & Df & Mean Square & $\mathrm{F}$ & Sig. & $\begin{array}{l}\text { Partial } \\
\text { Eta } \\
\text { Squared }\end{array}$ \\
\hline \multirow{12}{*}{ non-smoker } & Corrected Model & $14045.490^{\mathrm{a}}$ & 11 & 1276.863 & 11.243 & .000 & .534 \\
\hline & Intercept & 229875.038 & 1 & 229875.038 & $2.024 \mathrm{E} 3$ & .000 & .949 \\
\hline & graphic & 10089.834 & 2 & 5044.917 & 44.420 & .000 & .451 \\
\hline & variety & 195.804 & 1 & 195.804 & 1.724 & .192 & .016 \\
\hline & price & 2760.687 & 1 & 2760.687 & 24.307 & .000 & .184 \\
\hline & graphic * variety & 11.517 & 2 & 5.758 & .051 & .951 & .001 \\
\hline & graphic $*$ price & 146.977 & 2 & 73.488 & .647 & .526 & .012 \\
\hline & variety $*$ price & 230.029 & 1 & 230.029 & 2.025 & .158 & .018 \\
\hline & graphic $*$ variety $*$ price & 610.643 & 2 & 305.322 & 2.688 & .073 & .047 \\
\hline & Error & 12265.941 & 108 & 113.574 & & & \\
\hline & Total & 256186.469 & 120 & & & & \\
\hline & Corrected Total & 26311.431 & 119 & & & & \\
\hline \multirow{12}{*}{ smoker } & Corrected Model & $24124.716^{\mathrm{b}}$ & 11 & 2193.156 & 37.293 & .000 & .792 \\
\hline & Intercept & 376000.068 & 1 & 376000.068 & $6.394 E 3$ & .000 & .983 \\
\hline & graphic & 13643.552 & 2 & 6821.776 & 115.999 & .000 & .682 \\
\hline & variety & 2440.297 & 1 & 2440.297 & 41.496 & .000 & .278 \\
\hline & price & 5768.533 & 1 & 5768.533 & 98.090 & .000 & .476 \\
\hline & graphic * variety & 605.165 & 2 & 302.582 & 5.145 & .007 & .087 \\
\hline & graphic * price & 650.189 & 2 & 325.095 & 5.528 & .005 & .093 \\
\hline & variety $*$ price & 484.582 & 1 & 484.582 & 8.240 & .005 & .071 \\
\hline & graphic $*$ variety $*$ price & 532.397 & 2 & 266.199 & 4.527 & .013 & .077 \\
\hline & Error & 6351.339 & 108 & 58.809 & & & \\
\hline & Total & 406476.122 & 120 & & & & \\
\hline & Corrected Total & 30476.054 & 119 & & & & \\
\hline \multicolumn{3}{|c|}{ a. $\mathrm{R}$ Squared $=.534($ Adjusted R Squared $=.486)$} & & & & & \\
\hline \multicolumn{3}{|c|}{ b. R Squared $=.792($ Adjusted R Squared $=.770)$} & & & & & \\
\hline
\end{tabular}

To inspect the impact of moderating variables, we performed regression analysis. Moderated linear regression forms an equation like this:

$$
\mathrm{Y}^{\prime}=\alpha_{0}+\Sigma \alpha \mathrm{iQi}+\Sigma \beta \mathrm{jPj}+\Sigma \gamma \mathrm{kQiPj}+\varepsilon
$$

where $\mathrm{Q}_{\mathrm{i}}$ is a level of quality cue, $\mathrm{P}_{\mathrm{j}}$ one of permeability variables and $\mathrm{Q}_{\mathrm{i}} \mathrm{P}_{\mathrm{j}}$ is the moderating effect of $\mathrm{P}_{\mathrm{j}}$ on Qi. $\alpha, \beta$ and $\gamma$ are regression coefficients, $\varepsilon$ is regression error and $\alpha 0$ is constant.

In present research, we used the "enter method" for including variables in regression. After eliminating insignificant relationships, we found that besides main factors, two other variable, 
"being a smoker" and "being a quitter" could predict the brand image. There were also variables that affected the way an individual interprets the cues to develop a brand image. In other words, there were moderating variables as follows: marital status moderated the relationship between price and brand image; number of cigarette-consuming companions (cCC) moderated effect of variety signs and finally, education and age of respondent moderated the effect of graphic quality. Table 2 articulates the regression coefficient of above mentioned variables. These variables could predict approximately $70 \%$ of brand image variations.

Based on aforementioned analysis we accepted $\mathrm{H} 7$ with $95 \%$ confidence.

Table 2. Regression coefficients of independent and moderating variables influencing brand image

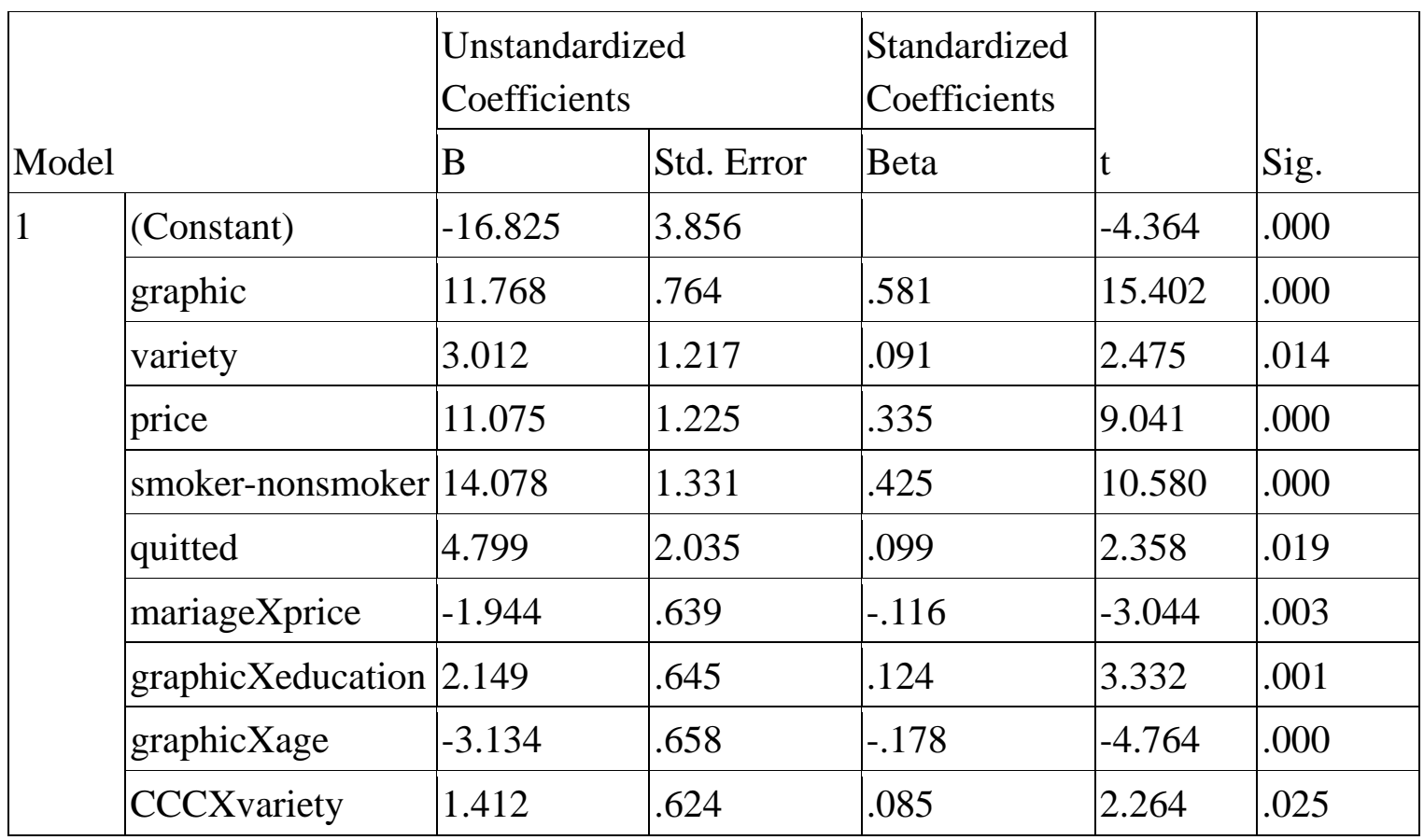

\section{Discussion}

There can be a justifiable argument against the validity of several researches that have measured brand image while creating a hypothetical condition in which all or some of branding elements of cigarette packs were eliminated (Wakefield et al 2008; Germain et al., 2010). In those cases, known as plain package researches, negative reaction of respondents to brands can be attributed to a transient psychological gap caused by loss of an ever-present quality.

In current research, we strived to treat the variables in a very credible fashion, i.e. introducing a new cigarette brand which can form an early perception in observer's mind.

We found results compatible with those researches affirming the impact of price on brand image or perceived quality (Taes \& Agarwal, 2000; Dodds \& Monroe, 1991). Graphic quality 
and price had been rarely studied as cigarette expected quality cues. We found that graphic quality was more of an informative cue for smokers and to even a larger extent for non-smokers. For the latter, we can see that they could not interpret the price levels easily, because of the unfamiliarity with actual product prices in real world and particularly because of the price surge in recent months, which tripled foreign cigarette prices. As for smokers, it's more fascinating to know why they found graphic more expressive than price. We beckon it was due to the research atmosphere that was not really about an economic decision but more about a cultural judgment. Interaction of graphic and price was also significant, suggesting that some of respondents accepted the worthiness of cigarette price only in presence of a decent graphic design.

The third external cue, existence of variety signs, were neglected by non-smokers but was comprehensible for smokers. It also had interaction with two other cues; that is, it could justify price and enhance graphic quality perception to some extent. All in all, observing mutual effect between factors only in smoker subgroup suggested how deeply a relevant observer might look at the different aspects of a message while an outsider just ignores it.

This research suggested that an old smoker with little education could find a bad graphic "decent", where a young educated one detested it. It also showed that single people tend to attribute higher prices to a better cigarette brand image and individuals who have more smokers around them, put more importance on variety signs.

We offered the concept of "permeability" to formulate different moderating effects that influence the way an individual interprets brand messages and develop brand image. This concept, borrowed from mechanics, can be symmetrized with traditional concept of receptivity, i.e. being exposed to a message (Feighery et al., 1998; Hurtz et al., 2007) to deepen the advertisement effectiveness planning/analyzing. In mechanics, permeability is a measure of the ability of a porous material to allow fluids to pass through it. In marketing, a message can be flown by a brand, but what can touch the targeted part of customer's mind, depends on how permeable is the "mental crust".

The research suggested that smokers and non-smokers had different levels of attention and/or different interpretations of external quality cues. It implied that not every single step that tobacco companies take would necessarily affect non-smokers along with targeted smokers. However, any further explicit conclusion requires more extensive academic and practical efforts. Next step might be re-conducting this experiment with a $3 * 3 * 3$ design and a larger sample. At the end, to broaden the scope of permeability idea, we might apply it in socio-cultural mass communications, where messages with huge receptivity remain un-interpreted, get rejected or arouse misinterpretations.

\section{References}

Aaker, D. A., \& Joachimsthaler, E. (2000). Brand leadership: The next level of the brand revolution. New York: Free Press 
Batra, R., \& Sinha, I. (2000). Consumer-level factors moderating the success of private label brands. Journal of Retailing, 175-191. http://dx.doi.org/10.1016/S0022-4359(00)00027-0

Biel, A. L. (1993). Converting image to equity. In Aaker, D. A., \& Biel, A. L (Eds.), Brand equity \& advertising: advertising's role in building strong brands (Vol. 1. Pp. 67-72). Lawrence Erlbaum.

Cohen, J. (1988). Statistical power analysis for the behavioral science, New York: academic press

Cooper, P. (1969). Subjective economics: factors in a psychology of spending. Pricing Strategy, 112-121.

Dobni, D., \& Zinkhan, G. M. (1990). In search of brand image: A foundation analysis. Advances in consumer research, 17(1), 110-119.

Feighery, E., Borzekowski, D. L., Schooler, C., \& Flora, J. (1998). Seeing, wanting, owning: the relationship between receptivity to tobacco marketing and smoking susceptibility in young people. Tobacco Control, 7(2), 123-128. http://dx.doi.org/http:/10.1136/tc.7.2.123

Fry, J. N. (1971). Personality variables and cigarette brand choice. Journal of Marketing Research, 298-304. http://dx.doi.org/10.2307/3149566

Germain, D., Wakefield, M. A., \& Durkin, S. J. (2010). Adolescents' perceptions of cigarette brand image: does plain packaging make a difference? Journal of Adolescent Health, 46(4), 385-392. http://dx.doi.org/10.1016/j.jadohealth.2009.08.009

Grewal, D., Krishnan, R., Baker, J., \& Borin, N. (1998). The effect of store name, brand name and price discounts on consumers' evaluations and purchase intentions. Journal of retailing, 74(3), 331-352. http://dx.doi.org/10.1016/S0022-4359(99)80099-2

Gwinner, K. (1997). A model of image creation and image transfer in event sponsorship. International marketing review, 14(3), 145-158. http://dx.doi.org/10.1108/02651339710170221

Hurtz, S. Q., Henriksen, L., Wang, Y. U. N., Feighery, E. C., \& Fortmann, S. P. (2007). The relationship between exposure to alcohol advertising in stores, owning alcohol promotional items, and adolescent alcohol use. Alcohol and Alcoholism, 42(2), 143-149. http://dx.doi.org/10.1093/alcalc/ag1119

Keller, K. L. (2003). Strategic brand management: building, measuring, and managing brand equity. Upper Saddle River, Prentice Hall.

Langhe, B. D. (2011). Contingencies: Learning Numerical and Emotional Associations in an Uncertain World. Erasmus University Rotterdam. 


\section{Macrothink}

Muthukrishnan, A. V., \& Chattopadhyay, A. (2007). Just give me another chance: The strategies for brand recovery from a bad first impression. Journal of marketing research, 334-345. http://dx.doi.org/10.1509/jmkr.44.2.334

Olson, J. C. (1974). Cue properties of price: Literature review and theoretical considerations (No. 20). College of Business Administration, Pennsylvania State University.

Olson, J. C. (1977). Price as an informational cue: effects in product evaluation. In A. G. Woodside, J. N. Sheth, \& P. D. Bennet, Consumer and industrial buying behaviour (pp. 267-286). New York: North-Holland Publishers.

Qomlaqi, R., \& Ghafoury, M. (2011). How branding mechanisms improve the return of quality, proceeding of $11^{\text {th }}$ conference of quality managers, Tehran, Iran (in Persian).

Wakefield, M. A., Germain, D., \& Durkin, S. J. (2008). How does increasingly plainer cigarette packaging influence adult smokers' perceptions about brand image? An experimental study. Tobacco Control, 17(6), 416-421. doi:10.1136/tc.2008.026732

Zeithaml V., \& Kirmani A. (1993). Brand Equity \& Advertising: Advertising's Role in Building Strong Brands, p145.

Zeithaml, V. A. (1988). Consumer perceptions of price, quality, and value: a means-end model and synthesis of evidence. The Journal of Marketing, 2-22. http://dx.doi.org/10.2307/1251446

Zinkhan, G. M., \& Hong, J. W. (1991). Self-concept and advertising effectiveness: a conceptual model of congruency, conspicuousness, and response mode. Advances in consumer research, 18(1), 348-354.

\section{Copyright Disclaimer}

Copyright reserved by the author(s).

This article is an open-access article distributed under the terms and conditions of the Creative Commons Attribution license (http://creativecommons.org/licenses/by/3.0/). 


\section{Macrothink Institute ${ }^{\text {TM }}$}

\section{Appendix}

Appendix 1. Hypothetical brand packs

A single red pack of each design represented low level of variety sign. One of 2 prices of 1500 Rls. Or 5500 Rls was printed on the card containing the cigarette pack photo.

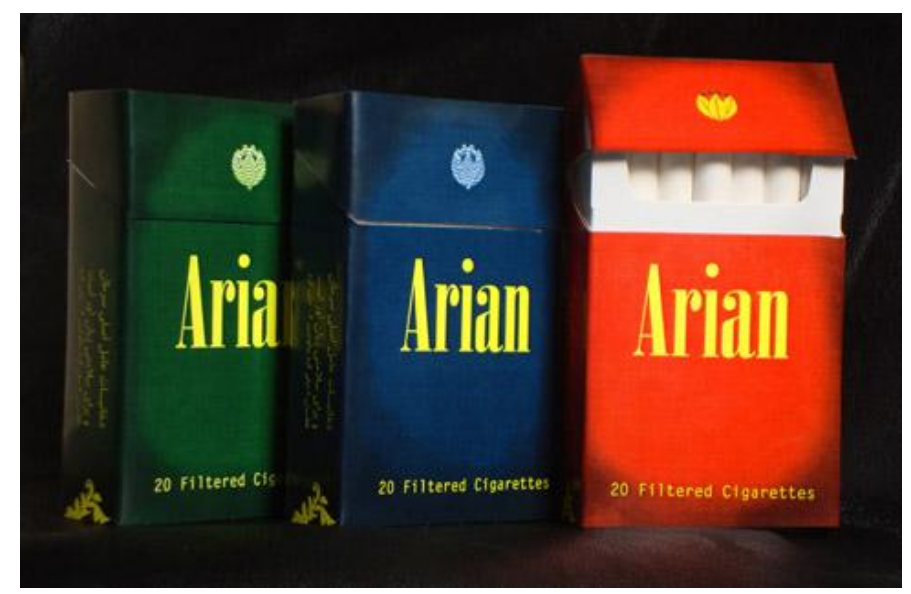

Graphic design- higher level

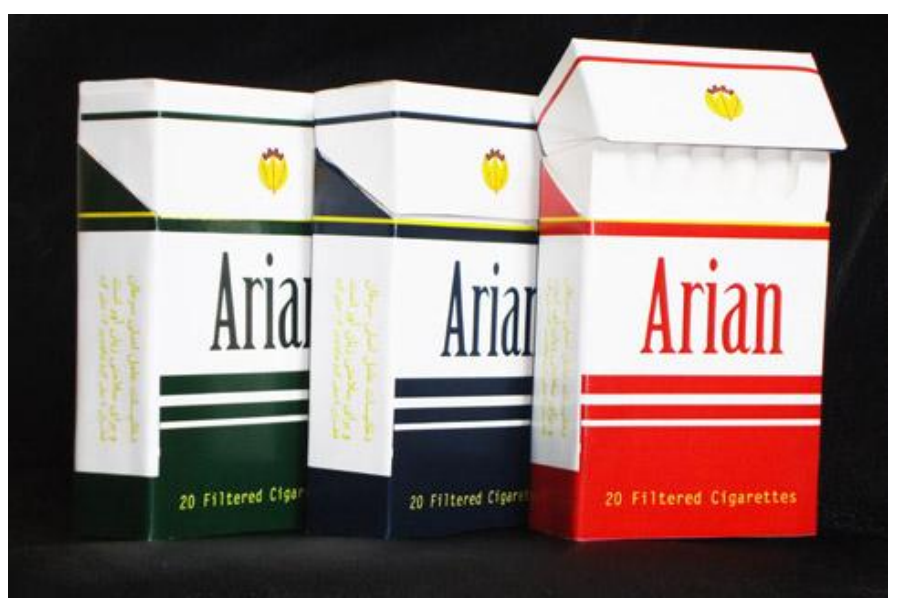

Graphic design- Intermediate level

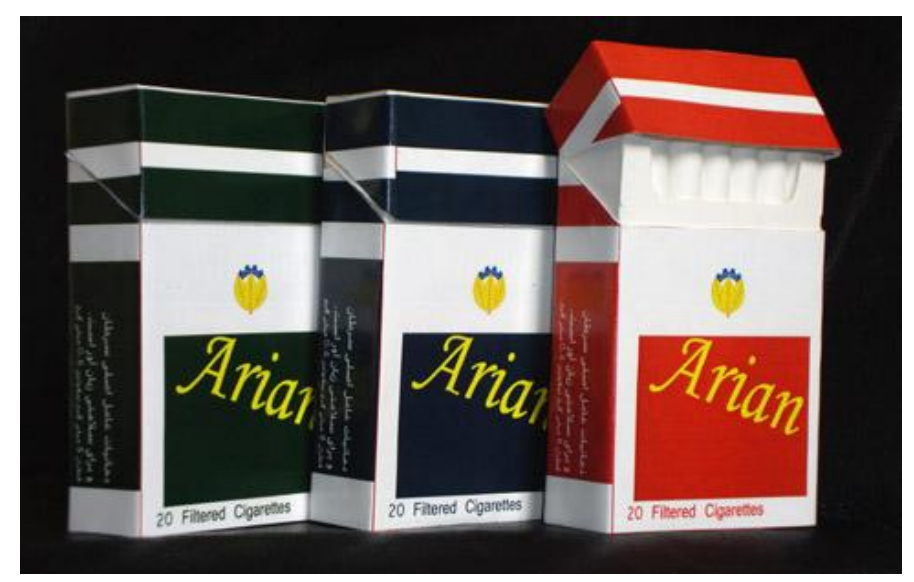

Graphic design- Low level 